Addressing the Causes of Malpractice Litigation

Dear Editors:

I agree with Thomas Cargill, Jr., when he states (in the June 1985 is sue) that if tort reform in malpractice litigation is necessary, "it should come, not through the creation of in stitutional biases, but by addressing the causes of phrsician/patient disputes."

Many doctor/patient disputes are, 1 think, caused by a poor doctor/patient relationship, which itself is causedaccording to patients' perceptionsby the physician's lack of sympathy or interest, or by his inattention.

Spending time with patients, caring, compassion, and sympathizing are or. dinarily considered to be inherent qualities of a physician's character, of his "bedside manner"; but obviously some doctors consider these qualities more important than do other doctors, and spend more time exercising them.

These services, if rendered conscientiously, do consume much time and effort on the part of the physician, so much so that the successfu rendering of these services is often in inverse proportion to the number of patients a physician sees per day. This is to say that the more patients a phy. sician sees, the less apt he is to be perceived by his patients as having those cualities of caring, compassion, and sympathy.

A phrsician's day can accommodate just so many responsibilities. Hospita rounds, phone calls to patients, talking to consultants, constant interruptions-all this in addition to seeing patients-place a very real strain on the physician's capacity to deliver those services (or qualities) of caring, compassion, and sympathy

In this light. it seems to me that the most important thing that physicians can do to decrease the number of doctor/patient disputes is to improve the doctor/patient relationship, and that means seeing fewer patients per day.

Edward J. Volpintesta, M.D

Bethel Medical Group

Bethel, Connecticut

\section{Tort Retort}

Dear Editors

The June 1985 issue of LAw, Mrid CNE \& HEALTH CARE published several items related to medical malpractice insurance and tort law reforms, starting with the President's Column and continuing with the conference re. port, " Can the Private Sector Find Re lief?': Review and Comment on the Urban Institute Conference on Medical Malpractice," and the commentary,

Insurance rates in many areas are skyrocketing while certain activities are becoming uninsurable.

"Variations on \$962,258: The Misuse of Data on Medical Malpractice." However, I would like to point out that medical malpractice is not isolated from all other possible liabilities that are insured. Insurance rates in many areas are skyrocketing while certain activities are becoming unin surable.

Recently our local public transportation authority was nearly unable to find a company to insure it. Local child-care institutions are unable to obtain insurance. In fact, not too long ago there was a newspaper report that lawyers themselves are having difficulty obtaining affordable malpractice insurance. Tort law that allows a convicted burglar to sue his victim for in juries he suffered after falling through a roof skylight in the process of committing the burglary seems to go beyond the pale of reason.

As Peter North Miller, chairman of Lloyd's of London, said last June, "Without reform of tort law in the united States there will not be a mar ket to cover the liabilities Americans want to see covered." This analysis cisagrees with that of the President's Column mentioned above, which seems to disagree with all the available evidence produced by the very people involved in providing liability insurance. All the malpractice in the world will not be compensated very much without insurance.

Sylvain Fribourg, M.D. F'anorama City, California
Medical Skepticism of Legal Ethics

Dear Editors:

I have now twice read Marshall Kapp's article, "The Bioethically In formed Attorney and the Humaniza tion of Medicine" (April 1985). While I recognize that much of this article is more in the nature of a review of several recent books in this area, I hope Mr. Kapp has not underestimated the enormous skepticism that he must meet in the medical profession re. garding any notion that attorneys will or are able to contribute to the "hu manization of medicine."

My understanding of legal ethics in the realm of medicine is quite simple: it's the law of the jungle. There are winners and there are losers, and as one football coach has been quoted: "Show me a good loser, and I'll show you a loser."

From your academic position, this is probably offensive; from my position in the front line of the daily practice of medicine, I assure you this is the ethical principle that I believe is followed by attorneys. I see little hope and have little desire to see this principle creep into the practice of medicine.

In sum, I sincerely hope that the ethical principles and moral precepts outlined in your article may be incor porated into the practice of law, and then perhaps we will see the bioethically informed attorney contributing to the "humanization of medicine."

Richard L. Kirby, M.D.

Salisbury, Maryland

\section{Call for Manuscripts}

The University of Utah Press will publish a series of about twenty-five titles over the next five years on the ethical implications of scientific research. Topics in progress range from genetic engineering, new reproductive techniques, and organ transplantation to geological hazard risk assessment. For further information, contact the series editors, Margaret Battin and Leslie Francis, Dept. of Philosophy, Univer. sity of Utah, Salt Lake City, Utah $8+112$, or call $801-581 \cdot 8161$. 